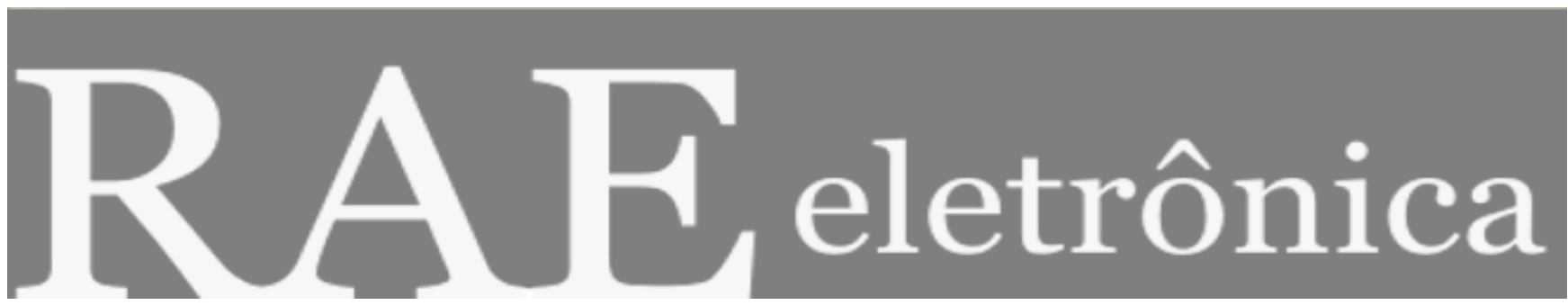

\title{
GÊNERO NAS ORGANIZAÇÕES: UM ESTUDO NO SETOR BANCÁRIO
}

Por:

Áurea Lúcia Silva Andrade

Mônica Carvalho Alves Cappelle

Mozar José de Brito

Alcielis de Paula Neto

Luiz Henrique de Barros Vilas Boas

RAE-eletrônica, Volume 1, Número 2, jul-dez/2002.

http://www.rae.com.br/eletronica/index.cfm?FuseAction=Artigo\&ID=1238\&Secao=COMPTO\&Volu $\mathrm{me}=1 \&$ Numero $=2 \& A n o=2002$

CCopyright, 2002, RAE-eletrônica. Todos os direitos, inclusive de tradução, são reservados. É permitido citar parte de artigos sem autorização prévia desde que seja identificada a fonte. A reprodução total de artigos é proibida. Os artigos só devem ser usados para uso pessoal e nãocomercial. Em caso de dúvidas, consulte a redação: redacao@rae.com.br.

A RAE-eletrônica é a revista on-line da FGV-EAESP, totalmente aberta e criada com o objetivo de agilizar a veiculação de trabalhos inéditos. Lançada em janeiro de 2002, com perfil acadêmico, é dedicada a professores, pesquisadores e estudantes. Para mais informações consulte o site www.rae.com.br/eletronica.

RAE-eletrônica

ISSN 1676-5648

(C)2002 Editora: Fundação Getulio Vargas - Escola de Administração de Empresas de São Paulo.

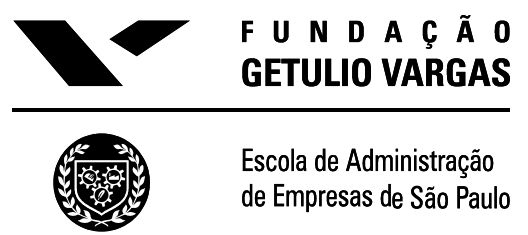




\section{GÊNERO NAS ORGANIZAÇÕES: UM ESTUDO NO SETOR BANCÁRIO}

\section{Áurea Lúcia Silva Andrade}

Professora dos cursos de Ciências Contábeis e Administração de Empresas da FUOM/FACIGE. Mestre em Administração pelo Programa de Pós-Graduação em Administração pela Universidade Federal de Lavras (PPGA/UFLA)

E-mail: aureals@ufla.br

Endereço: Rua Renato Aquino de Pádua, 273/3 - Vila Éster - Lavras - MG, 37200-000

Interesse de pesquisa: Recursos Humanos, Relações de Gênero nas Organizações, Influência da Tecnologia nas Relações de Trabalho.

\section{Mônica Carvalho Alves Cappelle}

Mestre em Administração pela Universidade Federal de Lavras, Doutoranda em Administração pelo CEPEAD/UFMG

E-mail: edmo@ufla.br

Endereço: Rua das Quaresmeiras, 36 Jardim Samaúma - Lavras - MG, 37200-000

Interesses de pesquisa: Relações de trabalho, relações de Gênero, Relações de Poder, Recursos Humanos

\section{Mozar José de Brito}

Mestre em Administração pela UFLA. Doutor em Administração pela USP.

E-mail: mozarjdb@ufla.br

Endereço: Depto de Administração e Economia-UFLA - Campus Universitário - Lavras - MG CP 3, 37000.000 .

Interesses de pesquisa: Organizações, Relações de trabalho e gestão de pessoas, Inovação Tecnológica e de Gestão.

\section{Alcielis de Paula Neto}

Mestrando em Administração pelo PPGA/UFLA

E-mail:nettoalc@,bol.com.br

\section{Luiz Henrique de Barros Vilas Boas}

Mestre em Administração pelo PPGA/UFLA; Doutorando em Administração pelo PPGA/UFLA

E-mail: riquevilas@navinet.com.br

Endereço: Rua Dr. João Silva Pena, 93, 402, Centro, Lavras - MG, 37200-000

Interesses de pesquisa: Relações de Gênero, Marketing, Comportamento do consumidor, Estratégia.

\section{RESUMO}

Este artigo se insere na área dos estudos organizacionais que trata das questões referentes às relações de gênero no espaço de trabalho, por meio do qual se buscou compreender como as categorias de pensamento sobre essas relações são "construídas" na subjetividade das pessoas e como atuam no desenvolvimento da carreira profissional de homens e mulheres em uma organização bancária. A relevância desta pesquisa se fundamenta na busca de compreender como os conflitos entre gênero são mediados dentro das organizações e de indicar possíveis soluções para potencializar o processo de gestão organizacional. Os resultados da pesquisa permitiram compreender que a hierarquia sexual 

ainda é imposta como mecanismo de diferenciação no âmbito organizacional, e que a coexistência de ambos os gêneros num contexto social comum pode ser capaz de transformar a realidade social. Estudos desta natureza reforçam a necessidade de as organizações buscarem novas formas de trabalhar a complexidade social sem inibir as diferenças existentes, pois assim cada um, em sua singularidade, pode contribuir efetivamente para o desenvolvimento organizacional.

\begin{abstract}
This article is inserted in the area of the organizational studies that treats with the gender relationships subjects in the work space, through which it was tried to understand how the thought categories about those relationships are "built" in people's subjectivity and how they act in men and women's career development in a bank organization. This research's relevance is based on the search of understanding how conflicts among gender are mediated within organizations and on indicating possible solutions for maximizing the organizational management process. The research's results allowed the understanding that sexual hierarchy is still imposed as a differentiation mechanism in the organizational ambit and that the coexistence of both genders in a common social context can be capable of transforming the social reality. Studies of this nature reinforce the organizational needs to search for new forms of working the social complexity without inhibiting the existent differences, because like this, each one, in their singularity, can contribute indeed to the organizational development.
\end{abstract}

\title{
PALAVRAS-CHAVE
}

Representações sociais, relações de gênero, espaço organizacional, pós-estruturalismo, realidade social.

\section{KEY WORDS}

Social representations, gender relationships, organizational space, post-structuralism, social reality. 


\section{INTRODUÇÃO}

As transformações constantes, o aumento da competitividade, juntamente com os avanços tecnológicos, tornam o ambiente no qual as organizações estão inseridas mais complexo e dinâmico, remetendo-as à convivência com uma maior diversidade interna. Essa diversidade aumenta a complexidade organizacional, mas pode ser também vista como um novo foco de riqueza para as organizações contemporâneas. O desafio é utilizá-la no desenvolvimento das organizações. Porém, para que isso seja possível, os ambientes organizacionais precisam ser mais flexíveis e transparentes, de forma a permitirem maior interação entre seus membros. Deve-se perceber a convivência de indivíduos com características diversas, não como mecanismo de distinção de oportunidades, mas como instrumento de potencialização de novas soluções e diferentes horizontes.

O aumento da diversidade e da complexidade nas organizações faz emergir novos tipos de contradições e assimetrias nesses espaços de interação social, como as questões referentes às relações de gênero. Nesse contexto, as organizações passam a ser o cenário de novas formas de conflitos, cuja gênese demanda discussão e compreensão e, cuja mediação depende da adaptação das práticas de gestão.

Acompanhando a trajetória dessas mudanças, os debates na academia sobre gênero ganham espaço o que permite um amadurecimento teórico-metodológico para trabalhar as questões que envolvem as relações sociais entre homens e mulheres no ambiente de trabalho. Nesse sentido, este artigo busca trabalhar as relações de gênero em uma ótica que supere a visão restrita às características biológicas. Além disso, buscam-se aqui mecanismos capazes de fazer emergir a subjetividade de cada indivíduo para entender o sentido da diferenciação nas relações de gênero.

Este trabalho é pautado na contribuição pós-estruturalista que coloca o gênero como um conceito compartilhado pela coletividade, trazendo à tona a necessidade de se trabalhar o universo simbólico das organizações. Ao trabalhar o universo simbólico, a abordagem pós-estruturalista possibilita uma convergência com a teoria das representações sociais. O conceito de gênero se aproxima, assim, da noção de representação social à medida que compreende formas compartilhadas, imagens, símbolos, sistemas de valores e referências, construídos por meio das interações com os outros e caracterizados a partir de um contexto sócio-histórico mais amplo (Medrado, 1996).

Em um estudo exploratório buscou-se desvendar as representações sociais em torno das relações de gênero em uma agência bancária, a fim de compreender como as categorias de pensamento sobre as relações de gênero são construídas dentro da organização. Ou seja, como as representações sociais sobre gênero são construídas na subjetividade dos indivíduos (homens e mulheres), além das conseqüências dessas construções nas relações de poder dentro da organização.

$\mathrm{O}$ artigo está estruturado em cinco partes. Na primeira, delimita-se o tema da pesquisa. Na segunda, apresenta-se uma fundamentação teórica que incorporou algumas reflexões sobre a abordagem pósestruturalista sobre gênero e a teoria das representações sociais, buscando uma interação entre essas duas teorias. Na terceira, discute-se os procedimentos metodológicos empregados no trabalho de campo. Na quarta, sistematiza-se uma reflexão acerca das representações sociais das relações de gênero na organização estudada. $\mathrm{Na}$ quinta parte, descreve-se as lições apreendidas com a realização desta pesquisa. 


\section{RELAÇÕES DE GÊNERO E REPRESENTAÇÕES SOCIAIS}

Esse item centra-se na busca da articulação entre as contribuições pós-estruturalistas e a teoria das representações sociais como eixos para a leitura da rede de relações entre homens e mulheres no ambiente de trabalho. Busca-se demonstrar que é possível a interação entre essas duas abordagens teórico-metodológicas e que, especificamente nesse estudo, a interação torna-se necessária, pois se complementam na análise do objeto em estudo. Assim, em um primeiro momento, descreve-se as contribuições pós-estruturalistas sobre gênero e, posteriormente, a teoria das representações sociais.

\section{Relações de gênero no espaço organizacional e suas representações}

A emergência do conceito de gênero, a partir da década de 1970, revela uma evolução teórica e propõe uma discussão que supera as análises restritas às características biológicas de cada sexo. A partir da inserção desse conceito, as relações entre homens e mulheres passam a ser consideradas como resultado de um processo que indica as construções históricas, sociais e culturais acerca dos papéis de cada um, abrangendo as identidades subjetivas. A abordagem pós-estruturalista enquadra-se nessa nova proposta de análise teórica (Calas e Smircich, 1999; Scott, 1988).

A abordagem pós-estruturalista, como corrente teórica, analisa as relações de gênero não como uma imposição, mas como um processo dinâmico que só pode ser compreendido no contexto em que é estabelecido. Nesse sentido, o contexto cultural é fundamental para entender as redes nas quais as relações de gênero estão imbricadas, pois a cultura tem uma relação com as formas de instrumentalização do poder dentro das organizações (Fleury, 1996). Considerando a cultura como pano de fundo das construções das relações de gênero, é possível perceber que a hierarquia sexual e as diferenciações decorrentes desse processo não são uma fatalidade biológica e sim, o resultado de um processo histórico, social e cultural (Deus, 1995).

A abordagem pós-estruturalista propõe, com base no pensamento de Derrida e de Foucault, a desconstrução da polaridade entre masculino e feminino e a reconceitualização de poder (Calas e Smircich, 1999). Essa visão permite que as análises abandonem as perspectivas pautadas nas interpretações biologistas, uma vez que os atributos e/ou características femininas e masculinas são compreendidos como histórica, social e lingüisticamente construídos (Louro, 2000a). Ao considerar o processo de construção das relações de gênero, a abordagem pós-estruturalista aponta a análise da especificidade de cada discurso como o caminho para fazer emergir as representações sociais sobre o gênero.

As pesquisas com respaldo na abordagem pós-estruturalista demonstram que não é o sexo o fator desencadeante das diferenças. Para os pós-estruturalistas o que desencadeia as diferenças é o significado socialmente construído de ser homem e de ser mulher. Ou, dito de outra forma, como homens e mulheres são «generificados» (Medrado, 1996).

Percebe-se, contudo, que o abandono do determinismo biológico não pode ser substituído pelo determinismo social, pois homens e mulheres podem ou não se posicionar segundo os parâmetros masculino e feminino pré-estabelecidos. Assim, é necessário considerar a dinâmica e a complexidade das relações de gênero que permeiam todo o ambiente organizacional já que essa dinâmica estabelece possibilidades de mudança (Medrado, 1996). 
COMPORTAMENTO ORGANIZACIONAL - GÊNERO NAS ORGANIZAÇÕES: UM ESTUDO NO SETOR BANCÁRIO Áurea Lúcia S. Andrade - Mônica C. Alves Cappelle - Mozar José de Brito - Alcielis de Paula Neto - Luiz Henrique de B. Vilas Boas As relações de gênero fornecem elementos para a compreensão do significado das relações de poder no espaço organizacional à medida que revelam como essas relações de poder legitimam determinado tipo de dominação em uma coletividade específica. Mediante o estudo do processo de construção de gênero, torna-se possível perceber um movimento de legitimação e de delimitação do espaço social, em que os indivíduos definem o "jogo de poder” existente nas relações sociais, conforme descrevem Meyer (2000) e Scott (1990).

\section{Representações sociais: a relação entre o indivíduo e a coletividade}

As representações sociais estão estritamente ligadas ao poder. Isso quer dizer que, por meio delas, pode-se estabelecer uma relação de manutenção e reforço da estrutura de poder estabelecida. Assim, pode-se inferir que as relações de gênero são pautadas no interior das representações sociais e que seus significados expressam e/ou refletem a estrutura de poder vigente. Portanto, a compreensão das representações sociais sobre as relações de gênero pode descortinar como a estrutura de poder é estabelecida e como as diferenças são construídas e/ou afirmadas.

A teoria das representações sociais originou-se de duas correntes teóricas representadas por F.H. Allport e por Serge Moscovici. Allport sofreu influência norte-americana e dos trabalhos de Comte, adotando uma posição que estabelece uma ruptura com o passado, característica da filosofia positivista da ciência. Já os estudos realizados por Moscovici, originaram-se na Europa e tiveram suas bases na Psicologia Social. Moscovici adotou de Durckheim o conceito de representação coletiva e, com isso, posicionou-se de forma oposta a Allport, perfazendo uma relação entre o passado e o presente. Moscovici procura explicar uma categoria coletiva em um nível inferior, justificando que diante da complexidade das sociedades modernas poucas representações são verdadeiramente coletivas. Esse caráter mais localizado, específico e contextualizado das representações sociais e a possibilidade de rompimento da polarização entre individualismo e coletivismo que elas permitem, em conseqüência, fazem com que estejam muito presentes nas teorias pós-modernas, adequando-se à investigação empírica das concepções leigas e fragmentadas da ciência (Farr, 1995). Por esse motivo, a vertente da teoria das representações sociais adotada neste trabalho é a que segue a fundamentação de Moscovici, distanciando-se da concepção mais positivista das representações sociais, originada em Alport.

A teoria das representações sociais busca as possibilidades de reconstrução teórica, epistemológica e metodológica, caracterizando-se assim como uma proposta teórica interdisciplinar. Seu potencial de convergir o conhecimento figurativo e o simbólico, caracteriza as representações sociais como um fenômeno que pode ser referido à construção de saberes sociais. Isso traz à tona a dimensão dos afetos, porque, quando sujeitos sociais empenham-se em entender e dar sentido ao mundo, eles o fazem com emoção (Guareschi e Jovchelovitch, 1995; Jovchelovitch, 1995; Medrado, 1996).

A coexistência dos indivíduos em sociedade é marcada pelo conflito entre o individual e o coletivo, considerado por Moscovici (1995) como realidade fundamental para a vida social. Esse conflito insurge e é promovido pelo confronto e tensão entre individualização e socialização que as normas formais elaboradas pelas instituições, existentes nas sociedades, conduzem a todo o tempo. Dessa forma, a construção de representações partilhadas permite uma certa regulação dessas tensões nos limites do suportável, pois não existe sujeito sem sistema, nem sistema sem sujeito, ou seja, vidas individuais, de acordo com Guareschi e Jovchelovitch (1995), só se formam e se constroem em relação a uma determinada realidade social. Nesse contexto, as representações sociais surgem na construção da relação do sujeito com o mundo, por isso precisam ser analisadas na realidade em que são engendradas, pois: "o sujeito não está subtraído da realidade social, nem meramente condenado a reproduzi-la; sua 
COMPORTAMENTO ORGANIZACIONAL - GÊNERO NAS ORGANIZAÇÕES: UM ESTUDO NO SETOR BANCÁRIO Áurea Lúcia S. Andrade - Mônica C. Alves Cappelle - Mozar José de Brito - Alcielis de Paula Neto - Luiz Henrique de B. Vilas Boas tarefa é elaborar a permanente tensão entre um mundo que já se encontra constituído e seus próprios esforços para ser um sujeito" (Jovchelovitch, 1995: 78).

Spink (1995) aponta que as representações sociais revelam o poder de criação e de transformação da realidade social que cada indivíduo pode potencializar, ou não. Assim, é impossível compreender a realidade a partir do indivíduo fechado em si próprio, pois, o comportamento do indivíduo só tem significado quando agregado a uma rede de relações. As representações sociais possuem núcleos tanto de transformação como de resistência em relação à forma de os indivíduos conceberem a realidade, demonstrando que a visão de mundo dos diferentes grupos expressa as contradições e conflitos presentes nas condições em que as representações foram elaboradas. (Minayo, 1995; Guareschi, 1995).

Apesar de a realidade social desempenhar um papel constitutivo na gênese das representações sociais, estas não são necessariamente conscientes. Como destaca Minayo (1995), as representações sociais permeiam a sociedade como algo habitual, que se reproduz a partir das estruturas e das próprias categorias de pensamento do coletivo ou dos grupos. Em suas palavras: "nelas (nas representações sociais) estão presentes elementos tanto de dominação como de resistência, tanto de contradições e conflitos como de conformismo" (op.cit., p.109).

Para Spink (1995), as representações sociais precisam ser compreendidas a partir do contexto que as engendra e a partir de sua funcionalidade nas interações sociais do cotidiano. Jovchelovitch (1995) reforça esse ponto quando coloca que as representações sociais expressam o espaço do sujeito na sua relação com o mundo e na sua busca para interpretá-lo, entendê-lo e reconstruí-lo. Nesse caso, a construção das representações sociais consiste em estratégias criadas pelos indivíduos para auxiliá-los a lidarem com situações que não podem ser alteradas no nível individual.

A teoria das representações sociais propõe: "articular tanto a vida coletiva de uma sociedade como os processos de constituição simbólica, nos quais sujeitos sociais lutam para dar sentido ao mundo, entendê-lo e nele encontrar o seu lugar, através de uma identidade social" (Jovchelovitch, 1995: 65).

A teoria das representações sociais contribui para a compreensão das práticas coletivas, por meio da análise dos discursos. A linguagem provê meios para a compreensão das representações sociais, pois os processos que engendram as representações sociais estão nas práticas de comunicação, como o diálogo e o discurso (Cavedon e Fachin, 2000; Minayo, 1995; Jovchelovitch, 1995). Farr (1995) reforça essa idéia afirmando que a linguagem é social e que é, provavelmente, a única fonte importante de representações coletivas. Orlandi (1996) argumenta que a linguagem ajuda a acionar as representações sociais ao apontar que o sujeito se apropria da linguagem num movimento social e não individual.

\section{Representações sociais e relações de gênero: uma interação possível e necessária}

A interação entre representações sociais e relações de gênero permite uma melhor discussão e compreensão do objeto de estudo. Essa opção teórico-metodológica permite analisar o objeto considerando sua complexidade.

As representações sociais e as relações de gênero descrevem a identidade coletiva de um grupo organizacional. Por meio da análise dos discursos é possível perceber como são compartilhadas as formas de poder, e quais mecanismos são utilizados como resistência e/ou aceitação da estrutura de poder vigente. Tanto as representações sociais, quanto as relações de gênero podem oferecer indícios de como o sujeito interpreta o ambiente à sua volta e qual o significado das relações estabelecidas nesse ambiente. Assim, é possível analisar as representações sociais sobre as relações de gênero e compreender como o poder é instrumentalizado dentro das organizações. Pode-se também identificar 
COMPORTAMENTO ORGANIZACIONAL - GÊNERO NAS ORGANIZAÇÕES: UM ESTUDO NO SETOR BANCÁRIO Áurea Lúcia S. Andrade - Mônica C. Alves Cappelle - Mozar José de Brito - Alcielis de Paula Neto - Luiz Henrique de B. Vilas Boas que mecanismos são usados para a manutenção de uma realidade social, que representa o conjunto de representações partilhadas capazes de assegurar a coexistência de diferenças individuais e divergências de interesses.

Percebe-se, assim, que considerar e analisar o conflito existente na sociedade é um ponto de partida para entender como se dão as relações de gênero e como atuam as representações sociais no ambiente em que são engendradas, visto que são construídas individual e coletivamente no imaginário das pessoas.

Os mecanismos que estabelecem as representações sociais têm origem no imaginário das pessoas, mas afetam as situações concretas por elas vivenciadas. Por isso, acredita-se que as representações sociais seriam um dos vários processos sociais que constituem a diferenciação de gênero. Essa constituição é constantemente construída e reconstituída (Louro, 2000b). A teoria das representações sociais contribui, portanto, para a compreensão das práticas coletivas, em especial, para a compreensão das relações de gênero.

Sob esta perspectiva, o gênero pode ser analisado em três posições: relacional, contextual/situacional e histórica. Ao considerar a dimensão relacional do gênero, reconhece-se que a distinção entre masculino e feminino só pode ser analisada a partir da relação entre os sexos (Medrado, 1996; Scott, 1995); a dimensão contextual/situacional aponta que os sexos são construções sócio-culturais e não biológicas, variando de acordo com a cultura que expressam (Mead apud Medrado, 1996); já a dimensão histórica destaca que o gênero é resultado de sua contextualização histórico-social (Scott, 1995; Medrado, 1996).

As representações sociais, por sua vez, podem ser construídas em três níveis, ou tempos distintos: o tempo curto, o tempo vivido e o tempo longo. O tempo curto envolve as interações sociais dos interlocutores para se comunicarem numa dimensão relacional; o tempo vivido corresponde ao período, ou situação, que compreende o processo de socialização dos indivíduos na cultura da qual fazem parte; e o tempo longo é de domínio do imaginário social e evolui de acordo com a dimensão histórica em que a análise das representações sociais está inserida (Spink, 1993).

De acordo com o exposto, as dimensões relacional-situacional-histórica do gênero correspondem, respectivamente, aos tempos curto-vivido-longo das representações sociais. Dessa forma, torna-se possível a convergência das duas abordagens teóricas, pois ambas percebem e trabalham a dinâmica psicossocial.

A abordagem pós-estruturalista e a teoria das representações sociais fornecem subsídios para a discussão de como as relações de gênero são construídas nas organizações. A conjugação dessas teorias permite um abandono do determinismo biológico e a inserção da problemática do poder, da resistência e do conflito, além de disponibilizar mecanismos para acessar a subjetividade dos indivíduos por meio da análise de seus discursos. Como as palavras são resultado de um processo sócio-histórico, é o discurso que dá sentido aos fenômenos que representam (Orlandi , 1996).

\section{EXPLORANDO AS RELAÇÕES DE GÊNERO: METODOLOGIA DE PESQUISA}

A questão da pesquisa foi trabalhada a partir de uma perspectiva qualitativa. O objetivo foi interpretar a teia de significados das relações entre homens e mulheres. Para tanto, tomou-se como unidade de análise uma agência bancária. Este trabalho procurou desvendar as representações das relações de gênero considerando um momento histórico específico, de forma parcial e limitada. Como estratégia de investigação, procurou-se adotar instrumentos capazes de trazer à tona as representações sociais na unidade analisada. Isso foi feito por meio da análise de discurso. 
COMPORTAMENTO ORGANIZACIONAL - GÊNERO NAS ORGANIZAÇÕES: UM ESTUDO NO SETOR BANCÁRIO Áurea Lúcia S. Andrade - Mônica C. Alves Cappelle - Mozar José de Brito - Alcielis de Paula Neto - Luiz Henrique de B. Vilas Boas Para alcançar os objetivos propostos para este trabalho, procurou-se fundamentar a trajetória metodológica nos trabalhos de Spink (1995). Ao sistematizar a análise dos discursos construídos pelos entrevistados em torno das relações de gênero, seguiu-se o roteiro: (1) realização de quatro entrevistas, sendo duas com homens e duas com mulheres; (2) transcrição das entrevistas; (3) leitura do material; (4) retomada aos objetivos da pesquisa e re-definição do objeto da representação; (5) construção de categorias analíticas que permitiram a sistematização das representações sociais. Os homens são identificados como $\mathrm{H} 1$ e $\mathrm{H} 2$ e as mulheres como M1 e M2.

A unidade de análise foi uma instituição bancária privada, situada em Minas Gerais. A instituição havia passado por recente processo de reestruturação e possui como política administrativa trabalhar com um número pequeno de funcionários. Especificamente na agência estudada, há apenas seis funcionários, sendo que a composição masculino/feminino é igual. Nos próximos itens discute-se, com base no arcabouço teórico-metodológico, os resultados do estudo empírico.

\section{As representações sociais das relações de gênero no espaço organizacional}

À luz da teoria das representações sociais e das correntes teóricas pós-estruturalistas que discutem as relações de gênero, procurou-se analisar como são construídas as representações sociais das relações de gênero em uma agência bancária e de que maneira essas representações afetam ou pressionam os atores sociais a usarem um discurso em defesa do status quo ou de negação da realidade.

Para facilitar a compreensão das representações sociais do trabalho feminino construídas pelas mulheres e pelos homens, dividiu-se a análise em três partes. Na primeira parte, analisou-se a relação mulher e trabalho com o intuito de perceber como são construídas as representações sociais sobre as mulheres no ambiente do trabalho. Posteriormente, analisou-se a relação mulher, família e maternidade, para identificar como o conflito inerente a essa relação é trabalhado pelas mulheres e como se processa a interação entre vida privada e vida profissional. Na terceira parte, observou-se como a relação é estabelecida entre mulher, carreira e profissionalização; ou seja, como são as representações sociais do aproveitamento da capacidade feminina na organização e como os homens e mulheres acessam as representações sociais a respeito da ascensão profissional das mulheres.

\section{A relação gênero e trabalho}

A análise do cenário onde as pessoas desenvolvem suas atividades profissionais permitiu compreender como as representações sociais sobre as relações de gênero são construídas no trabalho. Não perdendo de vista que as relações de gênero estabelecidas no ambiente de trabalho também conotam a história de cada indivíduo nele envolvido, observaram-se algumas contradições numa mesma entrevista. Isso nos indica o quanto a posição dos entrevistados - homens e mulheres - é ambígua e talvez dependente e/ou influenciada por posições hierárquicas ocupadas pelos mesmos.

$\mathrm{O}$ entrevistado $\mathrm{H} 1$ afirmou que "o ambiente de trabalho deve ter homens e mulheres", contudo, no decorrer de sua fala, ao tentar explicar como são as relações com clientes, mencionou que "ainda há no ser humano a imagem de que o homem que tem que decidir".

Ao afirmar que o ambiente de trabalho 'deve' ser composto por homens e mulheres, o entrevistado demonstra uma abertura à participação da mulher no trabalho, mas analisando a seqüência de seu discurso percebeu-se que ainda se posiciona de forma a delegar ao homem maior poder de decisão. A ligação que realiza entre tomada de decisão e masculinidade é fundamental para a percepção de que o espaço da mulher é deliberadamente limitado a cargos e funções que não envolvem maior poder ou participação no processo decisório. Essa realidade é percebida também em outras organizações as 
quais, muitas vezes, recrutam a mulher mas não permitem que a carreira feminina tenha a mesma trajetória da carreira masculina, especialmente, no que se refere a oportunidades de crescimento e remuneração.

A limitação da participação da mulher no processo de decisão é confirmada no discurso da entrevistada M1 "dependendo do cargo, homens ocupam 90\% das vagas", no qual ela se refere à distribuição de cargos de posição hierárquica superior e que envolvem maior poder de decisão. Essa entrevistada reafirma as distinções quando coloca de forma contundente que "há distinção entre ser mulher e ser homem" no ambiente de trabalho.

A discrepância em relação à ocupação de cargos mais ligados ao processo decisório também é relatada em trabalhos realizados em organizaçoes de outros setores como enfermagem (Meyer, 2000) e magistério (Louro, 2000a).

A percepção do fenômeno « teto de vidro » é reforçada pelo discurso de muitas mulheres que reforçam a diferenciação como natural. As mulheres, em muitas ocasiões, repetem o discurso masculino e projetam nelas próprias a responsabilidade por qualquer diferenciação no trabalho. A entrevistada M1 ilustra isto quando fala que "a mulher é que dá margem à discriminação. A maioria não sabe se impor".

A contradição está presente tanto no discurso feminino, quanto no discurso masculino. Os entrevistados mencionam que no ambiente organizacional deve haver homens e mulheres e que esses possuem as mesmas condições, mas, em contrapartida, observam que a decisão é mais ligada à figura masculina. As entrevistadas denunciam que os cargos que envolvem maior poder de decisão são mais direcionados aos homens, mas colocam-se como responsáveis por essa situação. A contradição nos discursos demonstra que o conflito dentro da organização é velado por algumas práticas que buscam camuflar as diferenças entre gênero.

A posição de dois entrevistados mostrou-se relevante pelo fato de que consideram que não há nenhuma forma de distinção no ambiente de trabalho. M2 chega a afirmar que " $90 \%$ das pessoas em geral consideram que a mulher tem o lugar dela". H2 aponta que, apesar de o mercado de trabalho ter sido inicialmente muito restrito para as mulheres, "hoje há mais espaço para as mulheres" do que para os homens.

A categoria de análise mulher e trabalho proporcionou condições para a compreensão da forma como a mulher é inserida no ambiente de trabalho. Percebeu-se que ainda há uma diferenciação entre homens e mulheres quanto à distribuição em cargos mais elevados, apesar do discurso assumido por ambos buscar uma dissimulação dessa realidade. A seguir, analisa-se como são construídas as representações sociais da relação mulher, família e maternidade.

\section{Representação social da relação mulher/família/maternidade}

A inserção da questão familiar é essencial no processo de compreensão da construção do discurso no ambiente de trabalho. Como as representações sociais são coletivas, mulheres e homens comungam idéias semelhantes quando relatam a importância da família. De acordo com a análise dos discursos, nota-se que as representações sociais sobre a família e maternidade são semelhantes tanto para homens, quanto para mulheres.

$\mathrm{Na}$ análise de dois depoimentos foi possível observar como os discursos representam a identidade coletiva: "tem mulheres que quando são mães precisam parar de trabalhar para cuidar dos filhos" 
COMPORTAMENTO ORGANIZACIONAL - GÊNERO NAS ORGANIZAÇÕES: UM ESTUDO NO SETOR BANCÁRIO Áurea Lúcia S. Andrade - Mônica C. Alves Cappelle - Mozar José de Brito - Alcielis de Paula Neto - Luiz Henrique de B. Vilas Boas (H1) e "a mulher é mais apegada à família" (M 1). Esses discursos levam a perceber que "o sujeito é um sujeito social, inscrito numa situação social e cultural definida, tendo uma história pessoal e social", conforme relatado por Spink (1995).

Assim, compreende-se porque homens e mulheres, em muitos casos, empregam o mesmo discurso e assumem uma mesma posição. Um exemplo é dado por H1 quando afirma que "(...) a mulher tem que ter apoio tanto do marido, quanto dos filhos (apoio familiar) para desenvolver as suas funções, ou seja, para trabalhar fora".

No instante em que a vida privada e a vida profissional são colocadas em uma mesma balança, tanto homens, quanto mulheres questionam-se se ambas possuem a mesmo peso e se podem e/ou devem ser analisadas sob a mesma medida. Para todos os entrevistados, a vida profissional concorre com a vida privada, principalmente, no caso da mulher. Como coloca M2, "para ter filho não dá não", admitindo que ser mãe concorre com sua vida profissional. Isso representa a reprodução do discurso e do modelo masculino. Percepções como essa foram observadas por Oliveira et al. (2000), que, além disso, colocam que as empresas ressaltam a necessidade e importância das mulheres interiorizarem aspectos masculinos para obterem ascensão profissional.

A família é, assim, concebida como essencial para a motivação e, ao mesmo tempo, empecilho para a dedicação à carreira, pois a importância da família é distinta para ambos e, por conseguinte, exige dedicação em intensidades diferentes. Isso coloca a mulher em posição de xeque no que se refere ao duo família e carreira. Contudo, percebe-se que nem os homens nem as mulheres sabem exatamente qual é o ponto de equilíbrio e qual papel devem desempenhar.

A representação social percebida nessa categoria de análise aponta que homens e mulheres acreditam que a vida profissional concorre com a vida privada da mulher no que tange a ser esposa e ser mãe, evidenciando, assim, que as representações sociais são coletivas e que, tanto para homens, quanto para mulheres, o papel de abdicar da carreira profissional para se dedicar à família cabe à mulher. As representações sociais que emergiram nos discursos mostram que se a prioridade feminina for a carreira, então, as mulheres devem reproduzir o modelo masculino. A fim de compreender melhor essas percepções, analisou-se a representação social da divisão sexual no processo de profissionalização e na carreira feminina.

\section{Profissionalização, carreira e o imaginário da divisão sexual do trabalho}

Com base na idéia de que o processo de socialização condiciona as funções desenvolvidas pelos sexos masculino e feminino, buscou-se entender como a carreira e a profissionalização são desenvolvidas na organização e como podem condicionar comportamentos e revelar modos de ver o mundo.

A análise dos dados de campo permitiu-nos afirmar que em falas semelhantes, homens e mulheres não percebem distinções no processo de ascensão na carreira profissional. Algumas afirmativas ilustram isso: "quanto à carreira, acho que não tem muita diferença não" (M1); "a participação das mulheres é positiva" (H1); "as pessoas aceitam as mulheres naturalmente e não demonstram nenhum preconceito" (M2).

Entretanto, em alguns momentos da pesquisa, percebeu-se que os entrevistados posicionavam-se de forma contraditória. Quando M1 diz "a mulher demora mais tempo que o homem para chegar a um cargo" e "(a mulher) tem que estar provando muito mais coisas", na realidade, está contradizendo a fala destacada anteriormente, quando afirma que não há diferenças entre homens e mulheres no que se refere à carreira. As duplicidades de posições indicam que as pessoas percebem distinções quanto ao 
COMPORTAMENTO ORGANIZACIONAL - GÊNERO NAS ORGANIZAÇÕES: UM ESTUDO NO SETOR BANCÁRIO Áurea Lúcia S. Andrade - Mônica C. Alves Cappelle - Mozar José de Brito - Alcielis de Paula Neto - Luiz Henrique de B. Vilas Boas gênero, mas, para seu próprio conforto e comodidade, acabam se posicionando de forma neutra, ou seja, o discurso adotado é usado como mecanismo de defesa. A análise destes discursos permite afirmar que fenômenos como o "teto de vidro", apontado por Calas e Smircich (1999) e Steil (1997), estão presentes na organização.

A observação das relações de gênero na unidade analisada revelou que a representação social da ascensão e profissionalização da mulher é diferenciada para homens e mulheres. E permitiu perceber que as mulheres enfrentam mais dificuldades para ocuparem posições de destaque profissional na empresa, confirmando vários trabalhos desenvolvidos sobre essa temática. A categoria processo de avaliação e desempenho permitiu novas observações, como exposto logo abaixo.

\section{Avaliação, desempenho e o discurso da igualdade}

O processo de avaliação tem respaldado no desempenho do profissional. No caso da unidade de análise, os entrevistados defenderam que o processo de avaliação e desempenho independe da questão de gênero. Um exemplo, segundo os entrevistados, é a eleição do "Funcionário Qualidade Semestral" que é realizada para que os colegas de trabalho avaliem uns aos outros nos quesitos: satisfação do cliente, iniciativa para a qualidade, espírito de equipe, trabalho organizado e disciplinado, redução de erros, redução de custos. Durante as entrevistas, foi ressaltado que o funcionário eleito no semestre em que se realizou a pesquisa foi uma mulher.

A análise do discurso de dois entrevistados mostra uma semelhança nas representações sociais de homens e mulheres no que se refere ao processo de avaliação no ambiente organizacional: "As pessoas são avaliadas de acordo com sua capacidade" (H1) e "Não há distinção no processo de avaliação entre homens e mulheres" (M2). Os dois entrevistados afirmam que a avaliação é coerente com o desempenho individual de cada um.

No entanto, ao resgatar uma observação feita anteriormente pela M1, na qual ela afirma que os homens ocupam a maioria dos cargos do alto escalão, pode-se perceber que esses programas são formas de atenuar as diferenças existentes. Isso demonstra que o discurso de igualdade esconde as diferenças existentes no espaço organizacional bancário.

Quanto ao desempenho, H1 fez uma observação que é importante destacar: “(...) o banco trabalha com poucos funcionários ... e, por causa deste fator, quando cai um problema em um funcionário(a), ele(ela) tem que resolver, independente se for homem ou mulher". Outra observação relevante foi feita por M2: "A qualidade do atendimento não depende do sexo feminino ou masculino". Esses discursos projetam a tendência da maioria das instituições financeiras que estão reduzindo o quadro de funcionários e delineia a aceitação desse movimento como imutável e inevitável.

De acordo com os entrevistados, a preferência do cliente não é caracterizada como dependente do sexo e sim, é reflexo da possibilidade de resolução de seus problemas. Como pode ser observado nessas duas falas : "Mas observo que as pessoas procuram o funcionário que está disponível para resolver o seu problema" $(\mathrm{H} 1)$ e "O cliente se dirige ao funcionário ou funcionária que vai resolver seu problema" (H2).

De uma maneira mais ampla, um entrevistado apontou que as diferenças de tratamentos entre o masculino e o feminino refletem a cultura de um país e que a mudança é um processo longo e demorado. As diferenças são percebidas, mas homens e mulheres muitas vezes não se posicionam de forma clara contra esse processo, fazendo com que se torne um ciclo vicioso. Isso confirma que as formas de ação e o discurso refletem as representações sociais de uma coletividade. 
No caso pesquisado, a não diferenciação de sexos em relação ao processo de avaliação e desempenho é um mecanismo para a mediação de possíveis conflitos. A adoção de um discurso comum promove a sensação de igualdade de oportunidades e pode funcionar como barreira para possíveis mudanças.

A seguir, apresenta-se como homens e mulheres elaboram as representações sociais sobre a mulher no âmbito profissional e como estas são compartilhadas pelos atores organizacionais estudados.

\section{CONCLUSÃO}

A discussão das relações de gênero no ambiente de trabalho encontra-se no em amadurecimento. O ambiente de trabalho deve ser compreendido como um espaço produtor de representações sociais e, principalmente, constitutivo de significações tanto para homens, quanto para mulheres.

No entanto, a compreensão do ambiente de trabalho deve ter como premissa que homens e mulheres são diferentes e que essas diferenças precisam ser respeitadas para que cada um, em sua singularidade, possa potencializar sua pluralidade. Parafrasenado M1 : "Esta coisa de igualdade não é bom. É bom saber que somos diferentes dos homens".

Apesar das contradições dos discursos e da percepção de que a atuação da mulher é limitada, percebeuse que a convivência de hoimens e mulheres num mesmo ambiente é a única forma para que a mulher possa construir sua identidade sem desconsiderar a realidade na qual está inserida. A discussão das questões que envolvem a mulher implicam, necessariamente, na discussão do papel do homem. Ou como observa Meyer forma (2000, p.6),"centrar-se na mulher não significa deixar de ter como referência a rede das relações sociais nas quais ela está envolvida".

A representação social é parcial à realidade que representa, pois a pesquisa nunca se esgota em si mesma e nenhum recorte é tão rico como a própria realidade. Com isso, a análise das condições nas quais um discurso se instaura deve ser descrita como o relacionamento entre os processos de produção desse discurso e o imaginário do indivíduo. A interação desses dois fatores - discurso e imaginário cria condições para que a situação vigente seja legitimada, ou potencializa a mudança do estado atual. Por isso, a discussão de gênero precisa trabalhar tanto o discurso assumido como buscar a subjetividade latente para que possa permitir a compreensão da forma que assume a interação homem/mulher no espaço organizacional.

A realidade é assim compreendida como fruto da relação e da interação entre homens e mulheres, pois, como apontam Guareschi e Jovchelovitch (1995), a mudança na sociedade é retratada pela mudança nas representações sociais, a qual ocorre, simultaneamente e complementarmente, no nível individual e no coletivo.

Nesse sentido, a análise dos discursos de homens e mulheres permitiu a percepção das categorias de pensamento que ambos constróem a respeito do que representa ser mulher numa agência bancária. Contudo, a percepção da realidade social é limitada porque nenhuma definição (recorte da realidade) dá conta de abarcar a totalidade do fenômeno. Assim, percebe-se a necessidade de novas pesquisas para a melhor compreensão das relações de gênero nas organizações.

\section{Artigo recebido em 04.09.2001. Aprovado em 11.06.2002}




\section{REFERÊNCIAS BIBLIOGRÁFICAS}

BECKER, H.S. Métodos de pesquisa em ciências sociais. São Paulo: Ed. Hucitec, 1993.

CALAS, B.; SMIRCICH, L. Do ponto de vista da mulher: abordagens feministas em estudos organizacionais. In : CLEGG, S.R.; HARDY, C. ; NORD, W.R. (orgs.). Handbook de estudos organizacionais. v. 1. São Paulo : Atlas, 1999.

CAVEDON, N.R.; FACHIN, R.C. Homogeneidade versus heterogeneidade cultural : um estudo em universidade pública. In: ENCONTRO NACIONAL DE PÓS-GRADUAÇÃO EM ADMINISTRAÇÃO, 24, 2000, Florianópolis. Anais... Florianópolis: ANPAD, 2000. CD-ROM.

DEUS, M.A.P.de. Estudos de gênero nos Cadernos de Pesquisa da Fundação Carlos Chagas - São Paulo. Viçosa: UFV. 1995. 164p. (Dissertação de mestrado)

FARR, R.M. Representações sociais: a teoria e sua história. In: GUARESCHI, P.A.; JOVCHELOVITCH, S. Textos em representações sociais. 2.ed. Petropólis : Vozes, 1995. p.31-59.

FLEURY, M.T.L. O desvendar a cultura de uma organização : uma discussão metodológica. In : FLEURY, M.T.L. ; FISCHER, R.M. (coord.). Cultura e poder nas organizações. 2.ed. São Paulo : Atlas, 1996.

GUARESCHI, P.A. Sem dinheiro não há salvação: ancorando o bem e o mal entre neopentecostais. In: GUARESCHI, P.A.; JOVCHELOVITCH, S. Textos em representações sociais. 2.ed. Petropólis : Vozes, 1995. p.191-225.

GUARESCHI, P.A.; JOVCHELOVITCH, S. Textos em representações sociais. 2.ed. Petropólis: Vozes, 1995.

JOVCHELOVITCH, S. Vivendo a vida com os outros: intersubjetividade, espaço público e representações sociais. In: GUARESCHI, P.A.; JOVCHELOVITCH, S. Textos em representações sociais. 2.ed. Petropólis: Vozes, 1995. p.63-85.

LOURO, G.L. Gênero e magistério: identidade, história e representação. 2000a. Disponível www.ufrgs/faced/geerge/duvida.html

LOURO, G.L. Nas redes do conceito de gênero. 2000b. Disponível www.ufrgs/faced/geerge/duvida.html

MEDRADO, B. A masculinidade nos comerciais de televisão. XX Reunião Anual da ANPOCS. Caxambu, 1996.

MEYER, D. E.E. A dúvida como postura intelectual : uma abordagem pós-estruturalista de análise dos estudos de gênero na enfermagem. 2000. Disponível www.ufrgs/faced/geerge/duvida.html 
MINAYO, M.C. de S. O conceito de representações sociais dentro da sociologia clássica. In: GUARESCHI, P.A.; JOVCHELOVITCH, S. Textos em representações sociais. 2.ed. Petropólis: Vozes, 1995. p.89-111.

MOSCOVICI, S. Prefácio. In: GUARESCHI, P.A.; JOVCHELOVITCH, S. Textos em representações sociais. 2.ed. Petropólis: Vozes, 1995. p.7-25.

OLIVEIRA, N.; OLIVEIRA, R. de C. M.; DALFIOR, S. D. R. Gênero e novas perspectivas de trabalho: um estudo junto a mulheres gerentes de atendimento no Banco do Brasil. In: ENCONTRO NACIONAL DE PÓS-GRADUAÇÃO EM ADMINISTRAÇÃO, 24, 2000, Florianópolis. Anais... Florianópolis: ANPAD, 2000. CD-ROM.

ORLANDI, E.P. Discurso e leitura. 3.ed. São Paulo: Cortez, 1996.

SCOTT, J. W. (1988) Gender: a usefull category of historical analysis. In: Educação \& realidade. Porto Alegre, v. 20, n.2. jul/dez, 1995.

SCOTT, J.W. Gênero: uma categoria útil para análise histórica. Educação e realidade. Porto Alegre. v.16, n.2. 1990. p. 5-22.

SCOTT, J.W. Gênero: uma categoria útil para análise histórica. In: Educação e realidade. Porto Alegre. v.20, n.2. Jul./dez. 1995. p. 71-99.

SPINK, M.J. O contexto como pretexto. In: ENCONTRO INTERAMERICANO DE PSICOLOGIA, 24, 1993, Santiado. Anais... 1993. CD-ROM.

SPINK, M.J. Desvendando as teorias implícitas: uma metodologia de análise das representações sociais. In: GUARESCHI, P.A.; JOVCHELOVITCH, S. Textos em representações sociais. 2.ed. Petropólis: Vozes, 1995. p.117-145.

STEIL, A. V. Organizações, gênero e posição hierárquica: compreendendo o fenômeno do teto de vidro. RAUSP, v.32, n.3, 1997.

TRIVIÑOS, A.N.S. Introdução à pesquisa em ciências sociais. São Paulo: Atlas, 1992. 